\title{
Conselhos de Administração: Análise de sua Composição em um Conjunto de Companhias Abertas Brasileiras
}

\author{
Marcos Galileu Lorena Dutra \\ Richard Saito
}

\section{Resumo}

O presente trabalho visa a identificar o perfil dos conselhos de administração de 142 companhias brasileiras listadas na Bolsa de São Paulo, a partir de dados do encerramento do exercício de 1999. Os conselheiros foram divididos em quatro categorias distintas, cujos critérios de separação seguiram a metodologia adotada por Bhagat e Black (2000). Foi avaliado o grau de independência do conselho de administração em relação aos acionistas controladores. Foram ainda realizadas análises para identificar características das companhias ligadas à sua composição acionária e situação patrimonial, que pudessem influenciar a composição do conselho, como existência de recibos representativos de ações, negociados no exterior, modalidade de exercício do controle e tamanho da companhia. Os resultados indicaram que os órgãos são amplamente dominados por representantes dos acionistas controladores e que há indícios de baixa utilização dos mecanismos de voto à disposição dos minoritários.

Palavras-chaves: governança corporativa; conselho de administração; conselheiros independentes; acionistas controladores.

\section{Abstract}

This paper analyzes the profile of board of directors of 142 Brazilian listed companies on the São Paulo exchange as of fiscal year ending December 1999. The board members were classified into 4 categories according to its degree of independence from the controlling shareholders - as per Bhagat and Black (2000). In addition, firm characteristics such as ownership structure, cross-listing and firm size were investigated to explain its likely influence on the composition of board of directors. The empirical research indicates that board members represent the interests of controlling shareholders, and that there is no evidence that minority shareholders do exercise their voting rights.

Key words: corporate governance; board of directors; independent directors; controlling shareholders. 


\section{INTRODUÇÃo}

O debate acerca da governança corporativa tem recebido crescente atenção da comunidade acadêmica e empresarial, envolvendo tópicos como o poder e a responsabilidade dos conselhos de administração, as regras relativas a aquisições hostis de controle acionário, a participação de investidores institucionais na gestão das companhias e as políticas de remuneração de executivos e conselheiros. A composição dos conselhos de administração é um dos temas centrais deste debate, e o escopo do presente trabalho é o estudo da capacidade de supervisão destes órgãos, a partir de uma visão crítica da sua composição.

Nos últimos anos, acadêmicos, associações profissionais e organismos multilaterais têm se dedicado à análise do perfil dos integrantes destes órgãos (Lodi, 2000). Um dos objetivos básicos é identificar quais as composições ideais para estes conselhos, de forma a tornar sua atividade de supervisão mais eficiente.

Uma das propostas mais intensamente discutidas e normalmente apresentada como recomendação, é a inclusão de determinado número de conselheiros independentes, que possam desempenhar suas funções sem influência da administração da companhia ou de grupos específicos de acionistas, especialmente controladores (IBGC, 2000). A idéia básica é a de que estes profissionais teriam uma atuação mais crítica e objetiva da atuação dos diretores (executivos) no interesse do conjunto de acionistas da companhia.

Apresenta-se aqui nova abordagem, que toma como parâmetro para a análise da eficácia de supervisão, a proporção de profissionais independentes presentes nos conselhos de companhias locais. Busca-se ainda identificar a participação dos acionistas não-controladores neste processo, mensurando o aproveitamento dos mecanismos de indicação de conselheiros por minoritários.

Assim, na próxima seção é efetuada revisão da literatura sobre a matéria, abordando-se a possibilidade de expropriação de acionistas minoritários pelos controladores, e a conseqüente necessidade do exercício da atividade de fiscalização pelos conselhos de administração. Na seqüência, são apresentados a metodologia e os resultados da pesquisa sobre a composição dos conselhos. A última seção é reservada para as considerações finais. 
REVISÃo DA LITERATURA

\section{A Concentração de Propriedade e os Indícios de Expropriação}

Na segunda metade da década de noventa do século passado, La Porta et al. (1998, 1999) desenvolveram uma série de estudos acerca das diferenças entre os diversos mercados de capitais nacionais. Um dos principais pontos destes trabalhos reside na identificação das causas e conseqüências da concentração da propriedade das ações, observadas em alguns países.

Uma das conclusões básicas dos seus estudos é que diferenças no grau de proteção dos direitos dos acionistas podem explicar alguns contrastes observados entre as características dos diversos mercados de capitais nacionais. Entre estes contrastes estão o grau de concentração da propriedade, a liquidez no mercado secundário, o tamanho relativo de cada mercado, as políticas de dividendos e o acesso a financiamento externo.

Este nível de proteção, por sua vez, varia de acordo com as características dos diversos arcabouços jurídicos e a efetividade da sua aplicação em cada um dos países. Empiricamente, os autores demonstraram que os acionistas estão melhor protegidos contra expropriações promovidas por executivos ou acionistas controladores em nações com sistema jurídico do tipo common $\operatorname{law}^{(1)}$ notadamente, Estados Unidos e Inglaterra.

Analisando uma amostra de 49 países, os autores sugerem que a concentração da propriedade acionária é negativamente relacionada à proteção dos direitos de acionistas, ou seja, países com melhor proteção tendem a apresentar maior dispersão da propriedade das companhias (La Porta et al., 1998). Separando-os por famílias de sistemas jurídicos, eles demonstraram que aqueles países com tradição jurídica herdada do código civil francês, categoria em que foi incluído o Brasil, apresentam maior grau de concentração da propriedade. Estudo posterior dos mesmos autores veio a demonstrar, ainda, que estes países com mecanismos menos eficientes de proteção aos acionistas possuem grande número de empresas sob controle familiar ou estatal e, no caso das primeiras, sem grande separação entre a propriedade e a administração da companhia (La Porta, Lopez-deSilanes e Shleifer, 1999).

Berndt (2000) defende que os direitos oriundos da propriedade das ações podem ser separados em duas modalidades distintas: os direitos de controle, que efetivamente implicam a possibilidade de indicação dos administradores das companhias e os direitos à participação na distribuição de dividendos. Nos países com 
maior concentração acionária, ambos são garantidos apenas aos acionistas controladores. Aqueles acionistas que não integram o grupo de controle, têm direito apenas aos dividendos e demais proventos pagos pela empresa, conforme as exigências legais.

Bebchuk, Kraakman e Triantis (2000) argumentam que esta separação, observável nos países de propriedade acionária concentrada, pode utilizar três mecanismos distintos: (1) estabelecimento de direitos diferenciados de voto para as diversas classes ou espécies de ações; (2) montagem de estruturas societárias piramidais; e (3) ocorrência de participações recíprocas entre as companhias. Um dos resultados desta dissociação de direitos, aliada ou não à concentração da propriedade das ações, é chamado na literatura de private benefits of control, ou benefícios privados do controle. Trata-se de um valor apropriado pelo controlador, que não é distribuído aos demais acionistas, o que, segundo Bebchuk (1999), constitui-se em incentivo para que em países com baixa proteção a acionistas minoritários, haja pequena dispersão dos direitos de voto.

Diversos estudos encontram indícios da ocorrência desta modalidade de apropriação de benefícios pelo controlador, como Barclay e Holderness (1989) e Nenova (2000). A última autora, após analisar 18 países, partindo de dados de 1997, comenta: "no Brasil, por exemplo, o controlador pode manter apenas um sexto do total de ações com direito a dividendos [metade mais uma das ações ordinárias, que podem chegar a um terço do capital total], mas de fato extrai (ou espera extrair) 37,5\% do valor da companhia. O benefício adicional expropriado representa um incremento de 21 pontos percentuais sobre a participação de um sexto correspondente aos dividendos" (Nenova, 2000).

Ainda no caso brasileiro, indícios da ocorrência desta apropriação de riquezas pelo controlador são também abordados por Cunha (2000). Segundo ele diversas companhias cujo bloco controlador foi alienado, apresentaram prêmios significativos pelo controle, como é o caso da Lacta (mais de $800 \%$ de prêmio em relação às cotações das ações no mercado), da Casa Anglo Brasileira (778\%) e da Artex (255\%). Para este autor, tais prêmios extraordinários refletem a idéia, disseminada entre os controladores, de que os ganhos advindos da propriedade do bloco de controle suplantam os benefícios resultantes de uma possível diversificação de suas carteiras de investimento.

\section{A Necessidade de Controle e o Conselho de Administração}

A questão da possibilidade de expropriação de parte do valor da companhia por acionistas controladores, conduz a discussão para a exigência de controle da atividade dos administradores. São necessários mecanismos que dificultem a 
adoção de medidas que beneficiem exclusivamente os controladores ${ }^{(2)}$, para que as ações não integrantes do bloco de controle sejam precificadas pelo mercado de forma eqüitativa.

Países com propriedade acionária concentrada, como o Brasil, não contam com o controle externo da administração da companhia - mecanismo em que os executivos passam a ser pressionados pela cotação das ações no mercado e pelo conseqüente risco de aquisição hostil do controle acionário, o que ocorre em países com mercados comparativamente mais desenvolvidos (Coffee, 2001). Quando há acionistas controladores detentores da maioria do poder de voto e mercados secundários menos líquidos, apresenta-se como alternativa aos minoritários a utilização de mecanismos de controle interno da administração, como é o caso do Conselho de Administração (Bratton e McCahery, 1999).

Trata-se de um órgão existente em todas as empresas de capital aberto, de caráter deliberativo, e integrado por profissionais eleitos pelos próprios acionistas. Suas atribuições estão apresentadas no art. 142 da Lei das Sociedades Anônimas - Lei 6.404, de 15 de dezembro de $1976^{(3)}$, que destaca, especificamente em relação às funções de controle, a fiscalização da gestão dos diretores, o exame de livros e papéis da companhia, dos contratos celebrados e quaisquer outros atos ligados à administração da empresa.

Em virtude desta atividade de fiscalização de atos dos diretores, tem ganho importância a discussão acerca da necessidade de independência dos conselheiros. Nos Estados Unidos, a preocupação maior reside na existência de conselhos, cuja maioria dos membros seja independente da diretoria - os chamados external directors, ou conselheiros externos.

Esta preocupação tem origem no fato de que, naquele país, os conflitos de agência são preponderantemente originários das divergências de interesses entre executivos e acionistas. Assim, caso o conselho de administração (denominado board of directors) apresente predominância de executivos, a sua liberdade para exercer controle efetivo sobre a administração da companhia estará comprometida.

Todavia países como o Brasil apresentam a propriedade acionária concentrada e, neste ambiente, conforme apontam Valadares e Leal (2000), os conflitos mais relevantes são observados na relação de acionistas majoritários (controladores) com minoritários. Assim, nestes países, a independência do conselho está ligada à maior ou menor influência dos acionistas controladores sobre seus membros, e não necessariamente àquela exercida pelos executivos, como em países cuja propriedade acionária é dispersa.

Nos Estados Unidos, a composição dos conselhos de administração foi farta- 
mente pesquisada, na maior parte dos casos analisando-se os efeitos de diferentes composições destes órgãos. Os resultados deste tipo de avaliação têm sido variados.

Rosenstein e Wyatt (1990) encontram evidências de retornos acima da média para as ações de empresas que divulgaram anúncios de indicação de conselheiros externos (não integrantes da diretoria) entre 1981 e 1985. Weisbach (1988) encontra indícios de associação significante entre desempenhos ruins das companhias e posteriores saídas do executivo principal, em instituições cujo órgão é dominado por conselheiros externos.

Outros estudos, porém, apresentam resultados divergentes. Byrd e Hickman (1992), por exemplo, mostram que há uma relação não linear entre a presença de conselheiros externos e a criação de valor para o acionista. Para tanto, mediram a reação do mercado em 192 anúncios de ofertas públicas entre 1980 e 1987. A relação torna-se negativa quando a proporção de externos ultrapassa $60 \%$ das vagas no conselho. Já Agrawal e Knoeber (1996), analisando o desempenho de 400 companhias americanas entre 1983 e 1987, identificam uma relação negativa e significante entre a maior presença de conselheiros independentes e o retorno sobre o preço de mercado das ações.

As pesquisas realizadas no país sobre a mesma matéria, sofreram forte influência da metodologia americana de se diferenciar conselheiros internos e externos. A mais detalhada delas é apresentada por Mônaco (2000), que analisa 647 companhias com registro na Comissão de Valores Mobiliários, usando dados de 1996. Os seus resultados foram os que seguem.

. 70,4\% dos conselheiros são considerados externos (não integrantes da Diretoria) e $29,6 \%$ internos.

. Em média, os conselhos possuem de 5 a 6 membros.

. São encontrados indícios de que a existência de acordos de acionistas está associada à maior presença de conselheiros externos, e de que empresas estatais apresentam conselhos com maior número de membros.

Mônaco (2000) defende ainda que o alto predomínio de conselheiros externos indica forte potencial de independência do órgão em relação aos executivos. Todavia é preciso ponderar que a separação entre conselheiros internos e externos, parte originalmente da idéia de que o conflito de interesses ocorre entre os executivos e os acionistas. Mensurando-se a participação de conselheiros internos, tem-se uma estimativa do grau de liberdade desfrutado pelos responsáveis pela gestão da companhia. Assim, um conselho composto majoritariamente por 
internos, pode indicar que existe menor intensidade no monitoramento, uma vez que estes conselheiros estariam supervisionando suas próprias atividades. Entretanto, conforme já discutido, em países com concentração acionária, o conflito ocorre mais especificamente entre controladores e minoritários. Assim, a diferenciação entre conselheiros externos e internos perde poder analítico, uma vez que no grupo de conselheiros externos podem estar incluídos acionistas que fazem parte do controle.

Deste modo, passa a ser de fundamental importância a identificação do grau de liberdade desfrutado pelo conselho de administração, para adotar medidas que protejam os interesses da totalidade do corpo de acionistas e não apenas de determinado grupo em particular - no caso, os controladores. No caso brasileiro, a aferição desta maior liberdade do conselho de administração não deve ser medida pela sua independência em relação aos executivos, mas em relação a estes acionistas controladores.

A problemática da liberdade desfrutada pelos integrantes dos conselhos é referida pelos principais Códigos de Melhores Práticas de Governança Corporativa. O Instituto Brasileiro de Governança Corporativa (IBGC, 2000), por exemplo, dispõe: "a razão fundamental da importância de independência é evitar conflitos de interesse. A maioria do Conselho deve ser formada por Conselheiros independentes. [...] O Conselheiro deve buscar máxima independência possível em relação ao acionista, grupo acionário ou parte interessada que o tenha indicado para o cargo".

Neste mesmo sentido dispõem ainda o Cadbury Report, produzido na Inglaterra (Lodi, 2000), e a Organização para a Cooperação e Desenvolvimento Econômico (OCDE), como recomendação a seus países membros (BOVESPA, 2000). Ambos também destacam a importância da inclusão de conselheiros independentes, buscando-se reduzir a ocorrência de conflitos de interesses.

\section{A Pesquisa}

\section{O Banco de Dados}

Visando ao estudo de empresas com ativa participação no mercado acionário, foi utilizada como base para a presente pesquisa o conjunto de companhias brasileiras, cujas ações negociadas nas bolsas de valores em 1999 representaram, no mínimo, 0,01\% do volume financeiro total movimentado nos pregões naquele ano. Como fonte de informações sobre a negociação de ações no 
mercado nacional, foi utilizado o relatório anual da Confederação Nacional das Bolsas de Valores (2000), que inclui as operações ocorridas nas 9 bolsas então existentes. Foi desconsiderada a negociação de ações no mercado de balcão, que proporcionalmente pouco representa em relação ao volume do mercado bursátil.

Deste grupo inicial, inicialmente composto por 154 companhias, foram excluídas 12 empresas, devido a ocorrências de cancelamento de seu registro de companhia aberta (3), incorporação por outras também integrantes do grupo em estudo (4), encerramento de atividades de natureza mercantil (1) e indisponibilidade de dados sobre o perfil dos conselheiros (4). Considerando tais ajustes, o grupo foi reduzido para 142 companhias.

A identificação dos integrantes dos conselhos de administração foi efetuada por meio da análise dos Informativos Anuais de 1999, enviados pelas companhias abertas à Comissão de Valores Mobiliários. Estes incluem a relação da totalidade dos membros eleitos após as assembléias de acionistas realizadas no primeiro semestre de 2000. Tais relatórios são obrigatoriamente apresentados pelas companhias até o fim do mês de agosto de cada ano e trazem informações sobre a composição do conselho de administração e da diretoria, além de dados sobre a atuação profissional pregressa e atual de cada um dos ocupantes de cargos nestes dois órgãos.

As últimas informações possibilitaram a classificação de cada um dos conselheiros em uma das quatro categorias apresentadas na seqüência, cujo critério de separação seguiu, com algumas adaptações, o modelo utilizado por Bhagat e Black $(2000)^{(4)}$.

- Conselheiro representante do grupo controlador: indivíduo que possui assento no conselho ou na diretoria de empresas pertencentes ao grupo controlador da companhia, ou que é membro da família detentora ou participante do controle, ou ainda integrante da esfera de governo que detenha ou participe do controle.

- Conselheiro interno: profissional que participa simultaneamente do conselho e da diretoria da empresa.

. Conselheiro afiliado: profissional que possui uma das seguintes características: (1) ex-funcionário da companhia ou grupo controlador; (2) funcionário ou beneficiário de fundação previdenciária patrocinada pela própria companhia; (3) representante eleito dos funcionários; (4) empregado sem cargo de diretoria; (5) ex-integrante do governo ou de companhia estatal que detenha ou participe do controle; e (6) diretor ou conselheiro de empresa controlada ou coligada. 
. Conselheiro independente: profissional sem ligação aparente com a companhia ou seus controladores.

Como a identificação dos conselheiros integrantes desta última categoria é uma tarefa mais complexa, foram computados como a ela pertencentes todos os profissionais que não puderam ser classificados em qualquer uma das outras três divisões. Tal critério advém da impossibilidade prática de se identificar os profissionais que sejam verdadeiramente independentes em relação à administração ou ao grupo controlador. Assim, o percentual identificado de conselheiros independentes reflete de forma apenas aproximada a verdadeira autonomia do conselho, e tal realidade não pode ser desconsiderada na análise dos resultados obtidos.

Em princípio, nos debates internos do órgão, os conselheiros são livres para decidir dentro dos limites legais estabelecidos. O posicionamento de cada integrante depende fundamentalmente de suas convicções a respeito da matéria em exame. Seu instrumental de análise e suas decisões dependem única e exclusivamente do seu convencimento acerca dos assuntos tratados. Seria razoável supor que esta liberdade é maior para os conselheiros independentes, pois eles estariam menos sujeitos a pressões por parte do controlador ou da administração. Assim, o pressuposto para os critérios de separação reside na concepção de que conselheiros independentes provavelmente realizarão um trabalho mais efetivo de defesa do valor das ações de acionistas não controladores, comparativamente ao papel esperado daqueles classificados como afiliados, internos ou controladores.

Para cada uma das companhias, foram ainda identificadas as seguintes variáveis: (1) participação dos controladores no capital total e no total de ações com direito a voto; (2) número de integrantes do conselho de administração; (3) modalidade de exercício do controle (se através de um único grupo econômico ou de forma compartilhada); (4) origem dos controladores (grupos nacionais, estrangeiros, controle estatal ou misto); (5) existência de recibos representativos de ações, negociados no exterior; e (6) valor total do ativo. Tais dados também foram obtidos nos Informativos Anuais de 1999 e nas Demonstrações Financeiras de 31/12/1999, disponibilizadas pela Comissão de Valores Mobiliários.

\section{A Composição dos Conselhos de Administração}

Efetuada a separação dos 1.058 conselheiros em cada uma das quatro categorias propostas e calculada a participação relativa de cada uma delas, foram obtidos os resultados apresentados na Tabela 1. 


\section{Tabela 1: Divisão dos Conselheiros de Administração das 142 Companhias Pesquisadas, por Categoria}

\begin{tabular}{l|c}
\hline Categoria & \% do total de conselheiros \\
\hline Controlador & $49 \%$ \\
Interno & $10 \%$ \\
Afiliado & $20 \%$ \\
Independente & $21 \%$ \\
\hline
\end{tabular}

Em uma primeira análise, a participação significativa de conselheiros do grupo controladores não surpreende, uma vez que a propriedade das ações com direito a voto é efetivamente concentrada - para evidências neste sentido, vide Siqueira (1998) e Valadares e Leal (2000). Assim, seria previsível que os acionistas controladores ocupariam maior número de assentos no conselho, para o efetivo aproveitamento dos benefícios advindos do controle, referidos em seção anterior.

Outra observação deve ser feita em relação aos conselheiros independentes: eles representam apenas $21 \%$ do total, um percentual que, observado isoladamente, sugere amplo desenquadramento das companhias locais em relação ao que sugerem o Cadbury Report e o Instituto Brasileiro de Governança Corporativa. Este destaque deve ser considerado ainda à luz do fato de que o número de independentes pode ter sido superestimado, dada a quantidade limitada de informações sobre o perfil dos conselheiros. Apenas a título de comparação, para um conjunto de 934 companhias americanas, em 1991, Bhagat e Black (2000) encontraram uma proporção de 64\% de conselheiros independentes, $12 \%$ de afiliados e $23 \%$ de internos (o seu estudo não incluiu a categoria de controladores).

A distribuição de empresas por faixa de participação de conselheiros externos no órgão produziu os resultados apresentados na Tabela 2.

Tabela 2: Participação de Conselheiros Independentes nos Conselhos de Administração

\begin{tabular}{c|c}
\hline $\begin{array}{c}\text { \% de independentes } \\
\text { em cada conselho }\end{array}$ & $\begin{array}{c}\text { \% das empresas } \\
\text { estudadas }\end{array}$ \\
\hline Menor que $24,9 \%$ & $58,5 \%$ \\
Entre $25 \%$ e $49,9 \%$ & $30,3 \%$ \\
Entre $50 \%$ e $74,9 \%$ & $10,6 \%$ \\
Acima de $75 \%$ & $0,6 \%$ \\
\hline
\end{tabular}


Observa-se que a proporção de conselheiros independentes é menor do que um quarto, em mais da metade das companhias pesquisadas. Apenas 12 empresas de um grupo de 142 atenderiam à recomendação de independência do IBGC.

Nestas circunstâncias, pode ficar comprometido o caráter de supervisão do conselho, pois a categoria de conselheiros independentes é francamente minoritária dentro da maior parte dos órgãos das empresas estudadas. Apenas em 16 empresas (11,2\% da amostra) eles constituem maioria (ou ao menos a metade do total de integrantes). Uma vez que o controle da administração no país é efetuado quase que exclusivamente por meio do sistema interno, esta composição dos conselhos indica que a eficácia do órgão na atividade de supervisão pode estar seriamente comprometida, no que tange à possibilidade de apropriação de benefícios pelos controladores.

No caso específico da pesquisa de Mônaco (2000), foi observada participação de quase $30 \%$ de conselheiros internos, enquanto que nas 142 companhias aqui estudadas, o percentual foi de apenas 10\%. Ocorre que há uma diferença significativa de metodologia entre uma e outra. Segundo o critério adotado por Mônaco (2000), um conselheiro que seja ao mesmo tempo vinculado ao grupo controlador e integrante da diretoria da companhia, seria classificado como interno. Já pela sistemática adotada nesta pesquisa, este mesmo conselheiro seria classificado como controlador, de modo que os resultados não podem ser comparados diretamente. Nestes termos, também não foi analisado o fato de que a presidência do conselho de administração pode ser ocupada pelo presidente executivo ou diretor-executivo, o que seria mais uma ocorrência de conselheiro interno, ou controlador, caso ele também pertencesse ao grupo detentor do controle.

\section{As Características das Companhias}

A divisão dos conselheiros nas diversas categorias e sua relação com as características de cada uma das companhias, resultou nas participações, como mostra a Tabela 3.

A partir dos dados apresentados na tabela, e com o objetivo de verificar se a composição dos conselhos é influenciada por cada uma das três variáveis em estudo (negociação de recibos de ações no exterior, origem do grupo controlador e natureza do controle), foi inicialmente utilizado o método do qui-quadrado.

Considerando-se a hipótese nula de que as variáveis são independentes, o uso do qui-quadrado para o teste do comportamento das três variáveis, a um nível de significância de 5\%, permitiu a rejeição da hipótese nula para a origem do controlador e a forma de exercício do controle; ou seja, os resultados obtidos na 
pesquisa permitem concluir que existe relação de dependência entre a origem do controlador (nacional, estrangeiro, estatal ou misto), a natureza do controle (controlador único ou controle compartilhado) e a composição do conselho de administração.

\section{Tabela 3: Influência das Características de cada uma das Companhias sobre a Composição dos Conselhos de Administração}

\begin{tabular}{l|l|c|c|c|c|c}
\hline $\begin{array}{l}\text { Variável } \\
\text { Medida }\end{array}$ & $\begin{array}{c}\text { Características } \\
\text { das } \\
\text { companhias }\end{array}$ & $\begin{array}{c}\text { Número } \\
\text { de } \\
\text { empresas }\end{array}$ & Controladores & Afiliados & Internos & Independentes \\
\hline $\begin{array}{l}\text { Negociação de } \\
\text { recibos de } \\
\text { açóes no } \\
\text { exterior }\end{array}$ & Não utiliza & 88 & $48,4 \%$ & $18,1 \%$ & $10,9 \%$ & $22,7 \%$ \\
\hline Utiliza & 54 & $48,8 \%$ & $22,7 \%$ & $9,7 \%$ & $18,8 \%$ \\
Crigem do & & & & & & \\
controlador & Nacional & 55 & $49,6 \%$ & $22,2 \%$ & $9,0 \%$ & $19,1 \%$ \\
& Estrangeiro & 50 & $48,7 \%$ & $13,5 \%$ & $12,8 \%$ & $25,0 \%$ \\
& Estatal & 17 & $37,6 \%$ & $32,0 \%$ & $11,2 \%$ & $19,1 \%$ \\
& Misto & 20 & $56,9 \%$ & $14,4 \%$ & $8,3 \%$ & $20,4 \%$ \\
\hline $\begin{array}{l}\text { Natureza do } \\
\text { controle }\end{array}$ & Controlador único & 101 & $44,7 \%$ & $20,8 \%$ & $11,5 \%$ & $22,9 \%$ \\
\hline & Compartilhado & 41 & $56,5 \%$ & $18,2 \%$ & $8,1 \%$ & $17,3 \%$ \\
\hline
\end{tabular}

Adicionalmente, foi ainda utilizado um modelo de regressão múltipla, com a consideração das três variáveis qualitativas supramencionadas (negociação de recibos de ações no exterior, origem do controlador e natureza do controle) e com a adição de quatro variáveis quantitativas já mencionadas em seção anterior (número de integrantes do conselho de administração, valor total dos ativos, participação dos controladores no capital total e com direito a voto). Tais características foram levantadas para a totalidade das 142 empresas estudadas, e consideradas de forma simultânea no modelo de regressão.

Foi utilizada como variável dependente a proporção de conselheiros independentes no conselho. Todavia não foram obtidos resultados satisfatórios, com baixos resultados para o $\mathrm{R}^{2}$, mesmo após a adoção de diversas transformações nas variáveis, análises univariadas e uso de procedimentos de stepwise; ou seja, os resultados obtidos com o modelo de regressão múltipla não permitem a rejeição da hipótese de independência da proporção de conselheiros independentes, em relação às demais variáveis.

\section{A Participação de Minorias e a Utilização de Voto Múltiplo}

A Lei das Sociedades Anônimas prevê dois mecanismos facilitadores da participação dos acionistas não controladores na eleição de membros para o conselho de administração(5) ${ }^{(5)}$ Ambos estão previstos no artigo 141 e em seu $\S 4^{\circ}$, que dispõe: 
“Art. 141. Na eleição dos conselheiros é facultado aos acionistas que representem, no mínimo, um décimo do capital social com direito a voto, esteja ou não previsto no estatuto, requerer a adoção do processo de voto múltiplo, atribuindo-se a cada ação tantos votos quantos sejam os membros do conselho, e reconhecido ao acionista o direito de cumular os votos num só candidato ou distribuí-los entre vários”.

"§ $4^{\circ}$ - Se o número de membros do conselho de administração for inferior a 5 (cinco), é facultado aos acionistas que representem 20\% (vinte por cento), no mínimo, do capital com direito a voto, a eleição de um dos membros do conselho, observado o disposto no $§ 1^{\circ}$ ”.

O chamado voto múltiplo, previsto no caput, consiste na atribuição, a cada ação, de um número de votos correspondente ao número de assentos no conselho. Assim, ao contrário da votação comum, em que cada ação ordinária corresponde a um único voto, nesta outra modalidade cada ação tem direito a, por exemplo, cinco votos, se for este o número de vagas no órgão.

Este mecanismo, segundo Carmo (1988), “constitui um modo eficaz de permitir às minorias acionárias agilizadas conseguirem uma representação no seio do Conselho de Administração. Pode transformar-se em instrumento perigoso para as maiorias, quando estas se dispersam e se desorganizam”.

De fato, por meio de uma estratégia de concentração dos votos em um ou mais candidatos, os minoritários podem se ver representados no conselho, o que, sem a ajuda do mecanismo, poderia ser difícil em face da alta concentração de ações nas mãos do grupo controlador. Os resultados da eleição dependeriam fundamentalmente do número de ações possuídas, do número de cargos a serem preenchidos e da forma de distribuição dos votos entre os candidatos.

Analisando-se o conjunto das 142 companhias em estudo, observa-se que 30 delas possuem conselhos de administração com um número de membros inferior a 5 (notadamente, com 3 ou 4 membros). Todavia, entre estas, apenas 18 possuem acionistas controladores cuja participação no capital ordinário é inferior a 80\%; ou seja, apenas nestas empresas haveria a possibilidade de indicação de um membro do conselho nos termos do $\S 4^{\circ}$ do artigo 141.

A Tabela 4 apresenta uma comparação da distribuição dos conselheiros por categorias, entre as empresas sujeitas à indicação de conselheiros pelo mecanismo previsto no $\S 4^{\circ}$ do artigo 141 e as demais companhias integrantes da amostra. 


\section{Tabela 4: Influência da Possível Participação de Minoritários na Composição dos Conselhos de Administração}

\begin{tabular}{l|c|c}
\hline $\begin{array}{l}\text { Categoria de } \\
\text { conselheiro }\end{array}$ & $\begin{array}{c}\text { Companhias sujeitas } \\
\text { ao } \$ 4^{\circ} \text { do art. 141 }\end{array}$ & $\begin{array}{c}\text { Demais } \\
\text { companhias }\end{array}$ \\
\hline Controlador & $64,4 \%$ & $47,6 \%$ \\
Afiliado & $6,8 \%$ & $20,7 \%$ \\
Interno & $11,9 \%$ & $10,3 \%$ \\
Independente & $16,9 \%$ & $21,3 \%$ \\
\hline Número de empresas & 18 & 124 \\
\hline
\end{tabular}

A análise estatística dos resultados permite identificar uma relação de dependência entre as categorias. Observa-se claramente que as companhias sujeitas ao uso da modalidade de voto prevista no $\S 4^{\circ}$ do artigo 141 apresentam menor participação de conselheiros independentes, o que não deixa de ser surpreendente. Seria esperada maior participação desta última categoria, caso os acionistas minoritários efetivamente utilizassem a possibilidade de indicação de um membro do conselho.

Tal constatação é ainda agravada quando se considera o número de assentos à disposição nos conselhos de cada uma das empresas. Para aquelas com três ou quatro vagas no conselho, a indicação de profissionais independentes representaria 33\% (para conselhos com três assentos) ou 25\% (para conselhos com quatro assentos).

Observando-se a relação das 18 empresas sujeitas à aplicação do $\S 4^{\circ}$, nota-se que 13 delas possuem 3 vagas no conselho, enquanto 5 outras companhias possuem 4 assentos. Assim, o percentual estimado das indicações de minoritários seria de $30,78 \%$ (25\% x 5/18 + 33\% x 13/18) para o conjunto das 18 empresas, uma proporção superior aos 16,9\% efetivamente observados.

Uma análise mais criteriosa da composição destas 18 empresas permite perceber que 6 delas (33\% do grupo) não apresentam qualquer conselheiro classificado nas categorias de afiliado ou independente. Excluídas estas empresas da análise, a participação de conselheiros independentes nas 12 restantes sobe para $25,0 \%$, contra um percentual potencial de 30,3\% (25\% x 4/12 + 33\% x 8/12).

Já no que se refere à utilização do voto múltiplo, observando-se o capital social das 142 empresas integrantes da amostra em estudo, e efetuando-se a sua comparação com os percentuais do capital ordinário constantes da Instrução CVM n. ${ }^{\circ} 282^{(6)}$, pode-se inferir que, a princípio, para 134 companhias o percentual 
mínimo requerido para adoção de voto múltiplo seria de 5\%; ou seja, o percentual inicialmente previsto em lei de $10 \%$ do total de ações ordinárias seria reduzido à metade com a aplicação das regras da Comissão de Valores Mobiliários.

Outras cinco empresas teriam como percentual necessário 6\%, uma delas 7\% e, as duas restantes, a parcela de $8 \%$ das ações com direito a voto. Todavia, nem todas as companhias possuem, distribuída entre acionistas minoritários, uma quantidade de ações correspondente ao percentual requerido pela Instrução da CVM. Observa-se que, em trinta casos, a parcela de ordinárias detida pelos acionistas controladores inviabiliza a requisição de voto múltiplo.

Assim, o grupo de estudo fica reduzido a 112 companhias. A todas elas foram enviadas correspondências por meio de correio eletrônico, endereçadas ao Diretor de Relações com Investidores, em que se questionou sobre a utilização do voto múltiplo na Assembléia Geral Ordinária ocorrida no ano 2000.

Responderam ao questionamento 43 companhias (38,39\% do total de empresas contatadas), o que, de certa forma, limita as possíveis conclusões que possam advir de um número tão baixo de respostas. Destas, apenas 3 empresas (7\% das respondentes) afirmaram que foi requerida pelos acionistas minoritários a utilização de voto múltiplo.

\section{Considerações Finais}

Os dados da pesquisa demonstram que os conselhos de administração são amplamente dominados por representantes dos acionistas controladores (49\%), havendo menor participação de profissionais independentes (21\%). Detectaram-se ainda indícios de influências da origem do controlador e da forma de exercício do controle sobre a distribuição dos conselheiros nas categorias propostas. As empresas que poderiam contar com representantes dos minoritários, seja por meio do voto múltiplo, seja com a indicação direta de um membro do conselho por detentores de pelo menos $20 \%$ das ações $\mathrm{ON}$, também não apresentaram maior participação de conselheiros independentes.

A princípio, tais resultados podem sugerir que a composição média dos conselhos de administração não permite o pleno exercício do seu papel de fiscalização das atividades dos executivos, no que se refere à ocorrência de conflitos de interesse entre acionistas controladores e minoritários. Aparentemente, medidas tomadas por executivos que venham a beneficiar este primeiro grupo, que fos- 
sem objeto de deliberação, encontrariam pouca resistência, uma vez que a maior parte dos conselheiros está vinculada aos controladores.

A pesquisa ainda demonstrou que os mecanismos legais que permitem a indicação de representantes dos acionistas minoritários, não implicam uma composição diferenciada do conselho de administração. Tal fato sugere que aparentemente há baixo interesse dos acionistas não-controladores pela participação nas assembléias e, conseqüentemente, pela indicação de representantes para o conselho de administração. Pode também indicar que há dificuldades para o exercício do poder de voto diante dos problemas no estabelecimento de mecanismos como proxy voting ${ }^{(7)}$, que permita delegar a terceiros, de forma célere, o direito de voto.

Em face dos indícios de baixa participação de acionistas não controladores na eleição de conselheiros, como observado na utilização do voto múltiplo, seria recomendável que a legislação ampliasse as possibilidades de indicação de conselheiros por acionistas não-controladores. Adicionalmente, outra sugestão para se tratar a questão seria impor mecanismos legais e regulamentares que impusessem obrigações aos investidores institucionais, para que eles participassem mais ativamente da gestão das companhias, tendo em vista seus menores custos de monitoramento em termos comparativos. Por fim, as entidades de autoregulação, como as bolsas de valores e as administradoras do mercado de balcão organizado, também poderiam adotar exigências de listagem, que incluam alterações nos mecanismos de eleição e responsabilização dos atos dos conselheiros de administração. Tais medidas poderiam propiciar maior acesso dos acionistas não controladores aos conselhos, de modo a atenuar a preponderância dos controladores no processo decisório, reduzindo-se assim eventuais ocorrências de conflito de interesses entre os dois grupos.

\section{Notas}

\footnotetext{
${ }^{1}$ Os sistemas jurídicos dos diversos países possuem duas origens básicas: o sistema da common law, originário da Inglaterra, e caracterizado por contar com juízes não especialistas, princípios legais amplos e tradição oral, e o sistema civilista, influenciado pelo Código Napoleônico e pela herança jurídica francesa, caracterizado por juízes profissionais, leis codificadas e tradição escrita. Para uma análise dos resultados sociais e ecônimicos de cada um dos sistemas, ver Glaeser e Shleifer (2001).

${ }^{2}$ Os mecanismos de transferência de riqueza da empresa podem assumir as mais diversas roupagens: transações entre a companhia e os acionistas controladores em condições desfavoráveis, uso de informações privilegiadas, integralização do capital com ativos superavaliados, incorporação de empresas controladoras e outras. Para maiores detalhes, ver Johnson (2000).
} 
${ }^{3}$ Não são consideradas neste artigo as alterações promovidas pela Lei 10.303/2001.

${ }^{4}$ No caso, a alteração em relação aos critérios de Bhagat e Black (2000) consistiu na inclusão da categoria de controladores, inexistente no modelo dos autores, pois eles analisaram o caso norteamericano.

${ }^{5}$ Conforme destacado, não são consideradas as alterações promovidas pela Lei 10.303/2001.

${ }^{6}$ A Comissão de Valores Mobiliários estabeleceu algumas regras específicas para a adoção do voto múltiplo, referidas nesta Instrução.

${ }^{7}$ Votação por meio de representantes munidos de instrumento de mandato (procurações).

\section{RefERÊNCIAS Bibliográficas}

AGRAWAL, A.;

KNOEBER, C. R.

Firm performance and mechanisms to control agency problems between managers and shareholders. Journal of Financial and Quantitative Analysis, v. 31, p. 377-390, 1996.

BARCLAY, M. J.;

HOLDERNESS, C. G.

Private benefits from control of public corporations. Journal of Financial Economics, v. 20, n. 2, p. 371-395, Dec. 1989.

BEBCHUK, L. A.
A rent-protection theory of corporate ownership and control. Cambridge, National Bureau of Economic Research Cambridge, 1999. NBER Working paper n. 7203.

BEBCHUK, L. A.; KRAAKMAN, R.; TRIANTIS, G. G.

Stock pyramids, cross-ownership, and dual class equity: the mechanisms and agency costs of separating control from cash-flow rights. In: MORCK, R. K. Concentrated corporate ownership. Chicago: University of Chicago Press, 2000. Cap. 10. p. 295-317.

BERNDT, M.

Global differences in corporate governance systems: theory and implications for reforms. [S.l.], Harvard Law School Cambridge, 2000. Discussion paper n. 303.

BHAGAT, S.;

BLACK, B.

Board independence and long term firm performance. New York, Columbia Law School, 2000. Working paper n. 143.

BOVESPA.

Princípios de governança corporativa da OCDE. São Paulo: Bovespa, 2000. 
BRATTON, W. W.;

MCCAHERY, J. A.

Comparative corporate governance and the theory of the firm: the case against global cross reference. Columbia Journal of Transnational Law, v. 38, n. 2, 1999.

BYRD, J. W.;

HICKMAN, K. A.

Do outside directors monitor managers? Evidence from tender offer bids. Journal of Financial Economics, v. 32, p. 195-221, 1992.

CARMO, E. de S.

Relações jurídicas na administração das S.A. Rio de Janeiro: Aide Editora, 1988.

CARVALHO, M. C.

IFC defende o direito dos minoritários. Gazeta Mercantil, São Paulo, 31 ago. 2000.

COFFEE, J. C.

The rise of dispersed ownership: the role of law in the separation of ownership and control. New York, Columbia Law School, 2001. Working paper $n$. 182.

CONFEDERAÇÃO NACIONAL DAS BOLSAS DE VALORES.

Relatório anual 1999. Belo Horizonte: CNBV, 2000.
CUNHA, M.

Governança corporativa e os players do mercado. In: A NOVA LEI DAS S.A. E A GOVERNANÇA CORPORATIVA, 2000, São Paulo. Anais... São Paulo: IIR Conferences, 2000.

GLAESER, E. L.;

SHLEIFER, A.

Legal origins. Cambridge, Harvard Institute of Economic Research, 2001. Discussion paper n. 1920.

INSTITUTO BRASILEIRO DE GOVERNANÇA CORPORATIVA.

Código das melhores práticas de governança corporativa. São Paulo, 1999.

JOHNSON, S. et al.

Tunneling. Cambridge, National Bureau of Economic Research, 2000. NBER Working paper $n$. W7523.

LA PORTA, R. et al.

Law and finance. Journal of Political Economy, v. 106, n. 6, p. 1113-1155, 1998.

LA PORTA, R.;

LOPEZ-DE-SILANES, F.;

SHLEIFER, A.

Corporate ownership around the world. Journal of Finance, v. 52, n. 2, p. 41-517, 1999. 
LODI, J. B.

Governança corporativa: o governo da empresa e o conselho de administração. São Paulo: Campus, 2000.

MAUTONE, S.

Respeito a minoritários tem gerado lucro. Folha de S. Paulo, 30 out. 2000.

MÔNACO, D. C.

Estudo da composição dos conselhos de administração e instrumentos de controle das sociedades por ações no Brasil. São Paulo, 2000. Dissertação (Mestrado em Administração) Faculdade de Economia, Administração e Contabilidade, Universidade de São Paulo.

NENOVA, T.

The value of corporate votes and control benefits: a crosscountry analysis. Boston, Harvard University, 2000. Working paper.
ROSENSTEIN, S.;

WYATT, J. G.

Outside directors, board independence and shareholder wealth. Journal of Financial Economics, v. 26, p. 175-191, 1990.

SIQUEIRA, T. V. de.

Concentração da propriedade nas empresas brasileiras de capital aberto. Revista do BNDES, n. 10, dez. 1998.

VALADARES, S. M.;

LEAL, R. P. C.

Ownership and control structure of brazilian companies. Revista Abante, v. 3, n. 1, p. 29-56, oct. 1999/abr. 2000.

WEISBACH, M. S.

Outside directors and CEO turnover. Journal of Financial Economics, v. 20, n. 1, p. 431460, Jan./Mar. 1988. 